\title{
Dilemas morales, conflictos entre derechos y conflictos "por" y "en" el derecho
}

\author{
Moral dilemmas, conflicts between rights \\ and conflicts "for" and "in" the Law.
}

Mauricio Maldonado Muñoz*

Recepción: 08/01/2018

Aceptación: 01/02/2018

Recepción y aceptación final: 11/04/2018

Resumen: En este ensayo me propongo retomar un debate planteado hace diez años en esta revista (Discusiones, 8, 2008). Se trata de la discusión de un trabajo de David Martínez Zorrilla acerca de los dilemas morales y el derecho, comentado luego por José Juan Moreso, Guillermo Lariguet, Eduardo Rivera López, Daniel Mendonca y Manuel Atienza. Me propongo, en lo esencial, sugerir un esquema que sirva para identificar los diferentes conflictos en el derecho. Para luego plantear cuáles, de entre aquellas situaciones, pueden identificarse como dilemáticas, sobre todo en el marco de los derechos fundamentales. Para esos efectos, plantearé objeciones a una de las tesis de Martínez Zorrilla, a la vez que me remitiré a otras dos de sus tesis que, en cambio, resultarán del todo relevantes para la reconstrucción propuesta.

Palabras clave: Dilemas morales, conflictos entre derechos, derechos fundamentales

Profesor de Filosofía del derecho, Universidad de Las Américas (Quito, Ecuador). Presidente de la Sociedad Ecuatoriana de Filosofía del Derecho (SEFiDe). Email: mmaldonadomunoz@gmail.com

Dedico este artículo a Cristina Redondo y a Pierluigi Chiassoni. Ambos invirtieron muchas horas de su tiempo discutiendo conmigo acerca de los conflictos y los dilemas. Me siento muy agradecido por ello.

En los casos en los que no se cita directamente la versión castellana, la traducción es mía. 
Mauricio Maldonado Muñoz

\begin{abstract}
In this essay I intend to resume a debate propounded ten years ago in this magazine (Discusiones, 8,2008 ). That is, the discussion of an article by David Martínez Zorrilla about moral dilemmas and law, commented by José Juan Moreso, Guillermo Lariguet, Eduardo Rivera López, Daniel Mendonca and Manuel Atienza. My proposal, in essence, suggests a scheme that could serve to identify different kinds of conflicts in law. Then I try to identify which, among those situations, can be identified as dilemmas, especially in the framework of fundamental rights. For these purposes, I will raise some objections to one of the thesis of Martínez Zorrilla, but also, in a second moment, I will refer to two of his thesis that will be entirely relevant to the proposed reconstruction.
\end{abstract}

Palabras clave: Moral dilemmas, conflicts between rights, fundamental rights.

For there is no end to the hopeful choices / still to be chosen. Lawrence Ferlinghetti, Endless Life

\title{
I. Introducción
}

Se dice que la tragedia griega nos proporciona, ya desde Esquilo, varios ejemplos de conflictos prácticos y/o dilemas morales ${ }^{1}$. Orestes debe vengar la muerte de su padre (Agamenón), pero también respetar a sus padres, y dado que la asesina de su padre es su madre (Clitemnestra), se plantea -para él- un dilema de no poco peso. Hefestos, en Prometeo encadenado, se lamenta diciendo que le faltan fuerzas para encadenar a un dios de su propia sangre en una cima azotada por las tempestades. Sin embargo, dice también que es preciso encontrar el valor para

1 Vid., v.gr., Nussbaum, M., "Aeschylus and Practical Conflict", Ethics, 95 (2), 1985, pp. 233-267. 
Dilemas morales, conflictos entre derechos y conflictos...

hacerlo, «porque desobedecer las órdenes del padre [Zeus] trae siempre graves males». Bien conocido es también el caso propuesto originalmente por el filósofo Carnéades, aquel en el que dos náufragos buscan salvarse y hay una sola tabla en el mar que no puede contenerlos a ambos $^{2}$. Es asimismo famosa la pregunta de Agamenón: «¿Qué curso de acción no produce males?» ${ }^{3}$. Y lo es porque allí se revela un problema -a veces trágico- de los dilemas morales: se estima que en estos casos es frecuente que cualquier decisión traiga consigo algún tipo de mal, que a veces no se puede sino escoger entre dos males.

Un hombre tiene frente a sí una palanca que puede cambiar el curso de un tren que va directamente hacia cinco personas atadas a los rieles. No obstante, también hay una persona atada a los otros, aquellos a los que la activación de la palanca dirigiría el tren. ¿Debería, el hombre del ejemplo, cambiar el curso del tren? Hacer o no hacer algo, en estas circunstancias, implica alguna pérdida sustancial. En este caso, la vida de una o cinco personas (there is no in-between $)^{4}$.

Pero fuera de los ejemplos literarios y de los experimentos mentales, puntualmente en el mundo del derecho, en algunas ocasiones nos encontramos también frente a problemas con estas características: casos que, dadas ciertas circunstancias, bien se pueden denominar trágicos ${ }^{5}$. En el año 2001 una Corte británica tuvo que decidir si dos hermanas siamesas debían o no ser separadas. La operación sacrificaría sin duda a una de ellas. No someterlas a la operación, en cambio,

2 Vid., Finkelstein, C.O., "Two Men And A Plank”, Legal Theory, 7 (3), 2001, pp. 279-306.

3 Vid., v.gr., Atienza, M., "Los límites de la interpretación constitucional. De nuevo sobre los casos trágicos", Isonomía, 6, 1997, pág.17.

4 Se trata de una de las tantas variantes del famoso ejemplo mental planteado originalmente por Philippa Foot: Foot, P., "The Problem of Abortion and the Doctrine of the Double Effect”, The Oxford Review, 5, 1967, pp. 5-15. En la literatura moralista, este caso es usualmente llamado The Trolley Problem. La etiqueta corresponde a Judith Jarvis Thomson: Thomson, J.J., "Killing, Letting Die, and the Trolley Problem", The Monist, 59, 1976, pp. 204-217.

5 No porque todos los dilemas lo sean necesariamente; esta es, de hecho, una cuestión disputada (como se aprecia también en el debate que ahora mismo comento), sino porque algunos de estos casos parecen contener este elemento, dadas las pérdidas sustanciales que producen, o pueden producir. 
suponía que de a poco ambas se irían apagando. Los padres de las siamesas no estaban dispuestos a permitir la separación, sobre todo por razones atinentes a su fe. Por su lado, los doctores del hospital consideraban que no realizar la operación implicaba dejar morir a la hermana que tenía posibilidades objetivas de sobrevivir, aunque ello supusiera un destino fatal para la otra ${ }^{6}$.

Hace diez años (2008) Discusiones publicó un número dedicado al debate de un trabajo de David Martínez Zorrilla acerca de los dilemas morales y el derecho. Se trata, según mi parecer, de una de las discusiones más interesantes y más apasionantes que haya publicado la revista. Y no sólo por el contenido del debate, apoyado en una bibliografía ingente, sino también por la valía de los participantes en dicha discusión. La presentación e introducción al debate fue realizada por José Juan Moreso. Por su parte, los trabajos críticos estuvieron a cargo de Guillermo Lariguet, Eduardo Rivera López, Daniel Mendonca y Manuel Atienza. Todo seguido de una respuesta a los críticos del propio Martínez Zorrilla ${ }^{7}$. Pocos años antes (2004) este autor había defendido su tesis en la Universidad Pompeu Fabra, la que dio lugar a una publicación, en torno a los "conflictos constitucionales", en la prestigiosa colección Filosofía y Derecho de la editorial Marcial Pons ${ }^{8}$. Vale recalcar, ya desde ahora, que los conflictos constitucionales, generalmente referidos a los así llamados conflictos entre derechos (o entre derechos y bienes públicos), suelen ser asimilados a los dilemas mora-

6 Este y varios ejemplos similares se encuentran en el primer capítulo de Carter L., Burke T, Reason in Law, Chicago, The University of Chicago Press, 2016.

7 Respectivamente: Martínez Zorrilla, D., "Dilemas morales y derecho", Discusiones, 8, pág.17-54; Moreso, J.J., "Dilemas morales, derecho y la decisión de Sophie", Discusiones, 8, pág. 7-16. Lariguet, G., "Dilemas morales y derecho. Una crítica a Martínez Zorrilla", Discusiones, 8, pág. 55-105. Rivera López, E., "Dilemas morales, discrecionalidad y azar", Discusiones, 8, pág.107-116. Mendonca, D., "Sobre el concepto de dilema moral", Discusiones, 8, pág. 117-127. Atienza, M., "Diez preguntas a Martínez Zorrilla", Discusiones, 8, pág. 129-133. Martínez Zorrilla, "Respuestas a los participantes", Discusiones, 8, pp. 135-172.

8 Martínez Zorrilla, Conflictos constitucionales, ponderación e indeterminación normativa, Madrid, Marcial Pons, 2007. 
Dilemas morales, conflictos entre derechos y conflictos...

les, por lo que las discusiones suelen intersecarse o emparentarse en más de un caso ${ }^{9}$. Más adelante volveré sobre este tema.

El debate aborda muchas cuestiones. Aquí enumero algunas: la definición de dilema moral y de conflicto constitucional, la posibilidad de que existan o no "genuinos" dilemas y/o conflictos constitucionales, la existencia o no de criterios para resolverlos (si es que existen), las posibles distinciones entre los dilemas y los (meros) conflictos morales $\mathrm{y} / \mathrm{o}$ constitucionales, la posible coherencia o consistencia de un sistema normativo moral y/o jurídico, la diferencia entre las obligaciones prima facie y las obligaciones definitivas, entre otras cuestiones. Obviamente, no todas son tratadas con la misma profundidad. Se podría decir que el debate es muy rico, aunque abigarrado. Esta riqueza y heterogeneidad hacen de la discusión algo inabarcable para un trabajo que debe ser, en lo posible, un balance. Y, quizás también, una especie de proyección hacia el futuro. De allí que abarcar todos los temas discutidos en ese número requeriría - tal como decía Guastini respecto a la obra de Bobbio $^{10}$ - un mapa de escala 1:1, como el que imaginó Borges en uno de sus relatos.

Pretendo hacer algo bastante más acotado. Ello, en la medida en que tengo la impresión de que cuatro temas sobresalen sobre los demás

9 Piénsese, por ejemplo, en el debate entre el especificacionismo (Specificationism) y el infraccionismo (Infrigment Theory), que ha oscilado entre la moral y el derecho: vid., v.gr. Thomson, "Some Ruminations on Rights", Arizona Law Review, 19, 1977, pp. 46-60; Feinberg, J., "Voluntary Euthanasia and the Inalienable Right to Life", Philosophy \& Public Affairs, 7 (2), 1978, pág. 93-123. Oberdiek, J., "Lost in Moral Space: on the infringing/violating distinction and its place in the theory of rights", Law and Philosophy, 23, 2004, pp. 325-346; Botterell, A., "In defense of infringement", Law and Philosophy, 27, 2008, pág. 269-292. Wellman, C.H., "On Conflicts Between Rights". Law and Philosophy, 14 (3-4), 1995, pp. 271-295. Webber, G.C., The Negotiable Constitution: On the Limitation of Rights, Cambridge, Cambridge University Press, 2009. Richardson, H.S., "Specifying Norms as a Way to Resolve Concrete Ethical Problems", Philosophy \& Public Affairs, 19 (4), 1990, pp. 279-310. Steiner, H., An essay on rights, Oxford, Blackwell, 1994. Shafer-Landau, R., "Specifying Absolute Rights", Arizona Law Review, 37, 1995, pp. 209-24. Moreso, J.J., "Conflictos entre principios constitucionales", en M. Carbonell (ed.), Neoconstitucionalismo(s), Madrid, Trotta, 2009.

${ }^{10}$ Guastini, R., "Il diritto", en V. Pazé (a cura di), L'opera di Norberto Bobbio. Itinerari di lettura, Milano, Franco Angeli, 2005, pág. 30 ss. 
(o que son, en todo caso, los más importantes para los fines que me propongo). Y son los siguientes: (1) si los dilemas morales pueden o no implicar más de un sistema normativo, (2) si pueden presentarse "auténticos" o "genuinos" dilemas morales, (3) qué relación puede tener la cuestión anterior con la presencia, en el derecho, de "genuinos" conflictos entre derechos, (4) si el recurso al azar puede resultar adecuado para la solución de (algunos de) los casos dilemáticos. En este trabajo me ocuparé de los tres primeros problemas, mientras que no me pronunciaré en absoluto sobre el cuarto. La razón para esta elección es muy simple: la dificultad admitida por el propio autor para defender posteriormente dicha posición, su talón de Aquiles en el marco del debate de la revista.

Frente al primer problema, Martínez Zorrilla sostiene que no se pueden dar dilemas morales en presencia de varios sistemas morales. Como explicaré más adelante, esta tesis resulta implausible: un dilema moral personal bien puede implicar diversos sistemas de normas, y un dilema moral interpersonal surge a menudo por la presencia de varios sistemas en competición. En cuanto al segundo y al tercer problema, en cambio, pienso que Martínez Zorrilla da en el blanco. En el marco de la segunda cuestión, Martínez Zorrilla señala que se puede distinguir entre las razones "no superadas" (prima facie) y las razones "definitivas" (all things considered). Para él, que un dilema moral "genuino" se presente o no depende del enfoque que se elija privilegiar: un conflicto entre razones no superadas es evidentemente posible, un conflicto entre razones definitivas, por su parte, no lo es. Este enfoque es, mutatis mutandis, extrapolable a la tercera cuestión: los conflictos entre derechos son posibles en la medida en que sean analizados como derechos prima facie o como derechos all things considered (con las precisiones que haré más adelante). Por último, en referencia a la relación que se da entre los dilemas morales y los conflictos entre derechos, nuestro autor apunta que ambos tipos de fenómenos pueden o no coincidir. Como dice el propio Martínez Zorrilla, esta equivalencia no es necesaria: no todo dilema moral refleja un conflicto constitucional, ni todo conflicto constitucional refleja un dilema moral. 
Dilemas morales, conflictos entre derechos y conflictos...

En lo que sigue, presentaré un cuadro general en el que trataré de identificar, en el marco del derecho, los distintos tipos de conflicto que pueden presentarse. Todo esto con el objetivo de analizar cuáles de ellos pueden prestarse a situaciones dilemáticas, y de qué tipo serían estas últimas. En el punto 2 hablaré brevemente sobre el problema relativo a la definición de dilema moral. En los puntos 3 y 4 analizaré qué tipos de conflictos se pueden identificar en el derecho, y cuáles de estos podrían ser identificados luego como conflictos entre derechos o podrían tener una incidencia sobre aquellos. En el punto 5 me concentraré en el debate entre aquellos que defienden la posibilidad de la existencia de conflictos "genuinos" entre derechos y aquellos que niegan tal posibilidad, discusión análoga respecto del debate acerca de la posibilidad de que se presenten o no dilemas morales "auténticos". En el punto 6, por su parte, abordaré el problema de la coincidencia o no, en determinados casos, de los dilemas morales y los conflictos entre derechos. Por último, en el punto 7, ofreceré una brevísima reflexión final.

\section{Definición de dilema moral}

Adoptaré, a efectos de este trabajo, una definición de dilema moral que no es la de Martínez Zorrilla. En su lugar, usaré una definición que estimo más "ecuménica", por decirlo de algún modo. Se trata de la definición (minimalista) de Mauro Barberis. En ésta, en una situación de dilema se debe elegir entre dos acciones que «(a) se excluyen mutuamente (no se puede hacer tanto la una como la otra) y (b) de las que ninguna de ellas es claramente preferible a la otra ${ }^{11}$. En realidad, la definición de Barberis debe ser parcialmente corregida, incluyendo en ella un tercer ítem: «(c) de las cuales ninguna sea indiferente». De otra manera, la definición de dilema moral de Barberis podría aplicarse

${ }^{11}$ Barberis, M., Ética para juristas, Madrid, Trotta, 2008, pág. 188. En realidad, la definición de Barberis se refiere a los casos en que un agente se encuentra en una situación dilemática. De tal manera que no incluye los casos de dilema moral interpersonal, de los que hablaré más adelante. De todos modos, dejando de lado ese aspecto, la definición de Barberis me parece adecuada. 
a situaciones que normalmente no consideramos dilemáticas. Podríamos tener que elegir entre dos manzanas más o menos iguales, sin poder escoger - por la razón que sea- ambas a la vez. Ninguna de las dos opciones es claramente preferible a la otra, de tal suerte que debe precisarse que las opciones a disposición no son indiferentes: sólo en ese caso podríamos hablar de un dilema ${ }^{12}$.

No se trata, nótese bien, de la imposibilidad de hallar criterios que nos permitan (al menos en determinados casos) obtener una respuesta satisfactoria a un dilema. Por el contrario, esta definición capta un aspecto de las situaciones dilemáticas sin comprometerse con asunciones sustantivas sujetas a discusiones bizantinas. De cualquier manera, de acuerdo a la definición de Barberis, los casos de dilema no se pueden resolver fácilmente de conformidad con nuestras intuiciones morales; y, por otro lado, producen escenarios en los que ambas obligaciones o derechos morales parecen, prima facie al menos, tener similar peso o importancia.

Por supuesto, desde este punto de vista, la calificación de un dilema moral como "genuino" o "aparente" podría estar sujeta a discusión. Barberis señala que un ejemplo de dilema "genuino" puede encontrarse en el famoso caso - usado y reusado por moralistas- del estudiante de Sartre; esto es, el caso del joven cuyo hermano ha muerto a manos del ejército alemán, y que se enfrenta al dilema de si debería ir a Inglaterra a unirse al ejército francés para pelear contra el ejército nazi, o bien quedarse en casa al cuidado de su madre enferma. El estudiante estima que debe ayudar a liberar a su país del yugo alemán, pero también que está obligado a cuidar de su desvalida madre. Para Barberis, como ya señalé, se trata de un "auténtico" dilema moral (asimétrico ${ }^{13}$ ). Yo, sin embargo, me inclinaría a pensar que se trata de un dilema "aparente". La madre del estudiante de Sartre depende enteramente de él. Y a menos que se hubiese tratado de Alan Turing o de algún militar desta-

12 Debo este apunte a José Juan Moreso.

${ }^{13}$ Son asimétricos los dilemas en los cuales son relevantes dos normas, mientras que son simétricos los dilemas en los que una sola norma o principio resulta relevante, como en el famoso caso de la “decisión de Sophie”. Barberis, M., Ética..., pp.188-189. 
Dilemas morales, conflictos entre derechos y conflictos...

cado de la época (que hubiese podido marcar la diferencia), me cuesta pensar por qué unirse al ejército tendría igual o más peso moral que cuidar de su anciana y desvalida madre.

Por supuesto, lo antedicho no implica que la definición de Barberis carezca de validez. Supone, nada más, que la calificación de un dilema moral como "genuino" o "aparente" puede estar sujeta a discusión. Ello, aún cuando sea común en la literatura relevante que algunos casos sean tratados como "casos claros" de dilema "genuino" (v.gr., el caso de "La decisión de Sophie", donde una madre, en medio de la tragedia de la Segunda Guerra Mundial, debe escoger cuál de sus dos hijos ha de quedarse con ella, condenando al otro a un destino fata ${ }^{14}$ ), y otros como "casos claros" de dilema "aparente" (v.gr., el famoso ejemplo platónico del depositario a quien un amigo le ha encargado una espada, y a quien éste le pide su restitución una vez que ha enloquecido). Nótese bien que esto no quiere decir que existan ontológicamente "casos claros" de dilema (genuinos o aparentes), simplemente quiere decir que en la literatura relevante es frecuente que algunos casos sean tratados como tales. No diré más a este respecto, salvo por algunas anotaciones marginales.

\section{Conflictos en el derecho: un primer esquema general}

En la antítesis jurídica guerra-paz, la paz es la ausencia de guerra, pero no la ausencia de conflicto. Dice Bobbio:

La paz y la guerra... son dos modos de resolver los conflictos sociales: la guerra mediante la fuerza de los mismos combatientes; la paz mediante el compromiso entre las partes y la atribución de la fuerza a una persona distinta de las partes.

${ }^{14}$ Sophie -en la novela de W. Styron- decide escoger a su hijo varón en lugar de su hija. La decisión la atormentará para siempre. Para un comentario al respecto, vid., Moreso, J.J., "Dilemas morales...", op. cit., pág. 12 ss. 
Más que un modo de eliminarlos, la paz jurídica es un modo de resolverlos cuando surgen ${ }^{15}$.

En ese sentido, los conflictos no desaparecen, sino que se transforman. Y lo que en una guerra o en una revolución puede ser representado como un conflicto por el derecho, se vuelve, en la paz, un conflicto en el derecho ${ }^{16}$. De ese modo, un conflicto en el derecho se configura de acuerdo a unas determinadas normas, conforme a las cuales luego ha de ser resuelto (en última instancia) por un tercero autorizado para tal efecto. En otras palabras, no desaparecen los conflictos, sino que cambia la forma de su resolución. Se asume, así, que el derecho es un instrumento específico de resolución de conflictos sociales que se decanta en la ejecución de determinados procedimientos y en el ejercicio de determinadas competencias ${ }^{17}$. Por extensión, se puede decir que existen ciertos conflictos por la constitución (como los que se presentan entre bancadas diversas de legisladores constituyentes; por ejemplo, entre liberales y socialistas por el establecimiento de unos determinados derechos en su texto), y otros conflictos en la constitución (que se resuelven conforme a sus normas ya establecidas) ${ }^{18}$. Del mismo modo, se puede hablar de conflictos por la legislación y de conflictos en la legislación. ¿Pero qué tipos de conflictos son estos? Como se verá enseguida,

15 Bobbio, N., "Formalismo giuridico e formalismo etico". Rivista di Filosofia, 1954, pp. 257-258.

16 Jori, M., Del diritto inesistente, Pisa, ETS, 2010, pág. 24.

${ }^{17}$ Desde un enfoque nomodinámico, dice Celano: «a los fines de una comprensión adecuada del derecho, la característica saliente -el elemento más iluminador- es el fenómeno de la autoridad, la institución de poderes de producción, eliminación y aplicación de normas o actos jurídicos mediante la especificación de las condiciones que los individuos o grupos de individuos deben satisfacer para ejercer tales funciones (es decir, la constitución de órganos de producción y aplicación del derecho) y de las condiciones -formas y modos- a que su actividad debe conformarse para poder valer como ejercicio de esas funciones (es decir, la especificación de procedimientos apropiados a los fines de la producción, eliminación o aplicación de normas o actos jurídicos)». Celano, B., "Justicia procedimental pura y teoría del derecho", en B. Celano, Derechos, justicia, razones, Madrid, Centro de Estudios Políticos y Constitucionales, 2009, pp. 23-24. 
Dilemas morales, conflictos entre derechos y conflictos...

los conflictos "por" y "en" el derecho pueden ser clasificados según los sujetos del conflicto, según los objetos del mismo, y según se trate del punto de vista intra-sistemático o extra-sistemático.

\section{III.1. Los sujetos del conflicto}

En el lenguaje de la teoría de juegos se distinguen dos grandes familias de juegos o conflictos: los conflictos cooperativos y los conflictos no-cooperativos $^{19}$. Me parece que se puede decir que el derecho, al menos en los regímenes contemporáneos, tiende a transformar ciertos conflictos cooperativos en conflictos no-cooperativos. ¿Pero en qué sentido? Pues bien, los conflictos cooperativos son, en términos generales, juegos de interacción estratégica en los que diversos "jugadores" con intereses comunes forman coaliciones o alianzas con el objetivo de lograr un resultado determinado. En el marco del derecho, podemos encontrar un ejemplo de este tipo en el caso de los conflictos por la constitución, así como también en el de los conflictos por la legislación, en la medida en que los legisladores (constituyentes u ordinarios ${ }^{20}$ ) plantean la inclusión de ciertos textos en determinados cuerpos normativos (la constitución, las leyes $)^{21}$, en general a través de la conformación de coaliciones que buscan que se imponga tal o cual texto normativo ("conflicto por el

${ }^{19} \mathrm{Al}$ inicio de un famoso trabajo, el célebre John Nash dice: «Von Neumann and Morgenstern have developed a very fruitful theory of two-person zero-sum games in their book Theory of Games and Economic Behavior. This book also contains a theory of n-person games of a type which we would call cooperative. This theory is based on an analysis of the interrelationships of the various coalitions which can be formed by the players of the game. Our theory, in contradistinction, is based on the absence of coalitions in that it is assumed that each participant acts independently, without collaboration or communication with any of the others» (Nash, J., "Non-cooperative games", Annals of Mathematics, 54 (2), 1951, pág. 286).

20 En el primer caso, detentores de un "poder constituyente", en el segundo, de un "poder constituido". Al respecto, vid., Guastini, R., La sintaxis del derecho, Madrid, Marcial Pons, 2016, pág. 157 y ss.

${ }^{21}$ Dado que se espera que estas "interacciones" se repitan con otros tantos textos y cuerpos normativos, este tipo de juegos constituyen -según la terminología de la teoría de juegos- "juegos repetidos (o iterados)". 
texto"), de manera que éste pase a formar parte de las disposiciones de un ordenamiento determinado ${ }^{22}$.

Ahora bien, una vez que estos textos se encuentran en vigor, el conflicto suele trasladarse al ámbito de los jueces. Las partes procesales, generalmente enfrentadas, plantean interpretaciones disímiles de los mismos textos normativos. Las mismas disposiciones, según el enfoque de estas partes, expresan normas antitéticas ("conflicto por el significado"). Sostiene Celano:

En la práctica del derecho, la interpretación es objeto de controversia y de argumentación. Los participantes presentan argumentos ("argumentos interpretativos") tendientes a acreditar la conclusión de que tal particular texto tiene tal particular significado. En otros términos, un rasgo peculiar (por supuesto, no exclusivo) del discurso jurídico es la propuesta y la defensa de hipótesis discordantes de interpretación de determinados textos, mediante la elaboración de inferencias que pretenden justificar la atribución de significados (en particular, normas) a significantes (en particular, disposiciones) ${ }^{23}$.

Pero también las partes suelen diferir acerca de la interpretación dirigida a los hechos. En estos casos, la interpretación dirigida a los textos puede no resultar conflictiva, de modo que las partes podrían concordar acerca de las normas vigentes aplicables a su caso, pero estar en desacuerdo acerca de los hechos subsumibles en relación a tales

22 Por supuesto, se puede pensar en ciertos cuerpos normativos (los reglamentos, los decretos) que son el producto, no de un órgano colegiado integrado por varios legisladores, sino del ejercicio de determinadas potestades que no requieren del concurso de otras autoridades para su aprobación. Justamente, en el caso de los reglamentos o los decretos generalmente se requiere de la sola voluntad del Presidente de la República, expresada en tal o cual texto normativo, para la dictación de un cuerpo normativo. De allí que, en sentido amplio, no todos los actos de legislación puedan ser descritos como juegos cooperativos. Se habla de un juego cooperativo solo en aquellos casos cuyo resultado depende de la interacción de diversas coaliciones de "jugadores" (como ocurre en las asambleas constituyentes o en las legislaturas ordinarias).

${ }^{23}$ Celano, B., Due problemi aperti dell'interpretazione giuridica, Módena, Mucchi, 2017, pág. 24. 
Dilemas morales, conflictos entre derechos y conflictos...

normas ("conflicto por la realidad procesal"). Es así que las partes procesales, en la lucha por el significado o por la realidad procesal, poseen intereses interpretativos diversos o enfrentados que no pueden resolver por sí mismos, de manera que deben tomar sus decisiones de forma independiente respecto de los otros "jugadores". Estos juegos (los conflictos en la constitución y en la legislación) se pueden definir como conflictos no-cooperativos ${ }^{24}$.

\section{III.2. Los objetos del conflicto}

Los conflictos de los que he hablado en el acápite anterior se enfocan en los sujetos del conflicto (en los "jugadores", de acuerdo al enfoque presentado), pero también el conflicto puede entenderse desde el punto de vista de su objeto. Como se vio en el acápite anterior, a veces en el derecho se presentan "conflictos por el texto", otras veces se presentan "conflictos por el significado", y otras tantas "conflictos por la realidad procesal". Estos representan tres objetos distintos (el texto, el significado y la realidad procesal), correspondientes a dos sedes diferentes: la creación y la aplicación del derecho.

No obstante, desde el punto de vista del sistema, un conflicto no es sino una antinomia (jurídica) entre normas. Una antinomia jurídica es un conflicto entre normas de la forma "Si H entonces C", o de la forma "P está permitido", "Q es obligatorio", "R está prohibido". El objeto del conflicto, en este caso, es la norma. De esta manera, se da una antinomia cuando para un mismo supuesto de hecho se encuentran previstas consecuencias jurídicas incompatibles, o cuando un comportamiento haya sido deónticamente calificado en modo contrastante (por ejemplo, prohibiéndolo y permitiéndolo a la vez) ${ }^{25}$. Esto se refiere, en realidad, a las así llamadas antinomias propias (lógicas); aunque también se pueden identificar otras de otro tipo, las así llamadas anti-

${ }^{24}$ Cfr., Celano, B., "El razonamiento jurídico: tres temas clave y lo que la filosofía puede (o no puede) hacer acerca de ellos", en B. Celano, Derechos, justicia, razones, Madrid, Centro de Estudios Políticos y Constitucionales, 2009, pp. 152-160. Celano, B., Due problemi..., op. cit., pág. 34 y ss.

${ }^{25}$ Guastini, R., “Antinomias y lagunas”, Jurídica-Anuario, 1995, pág. 437 y ss. 
nomias impropias (teleológicas, axiológicas) ${ }^{26}$. Estas últimas se refieren a las contraposiciones a nivel de principios (conflictos entre principios, frecuentemente conflictos entre derechos), como cuando se dice que se presenta una colisión entre la libertad de expresión y el honor, la libertad y la seguridad, la igualdad y la libertad, etc ${ }^{27}$.

\section{III.3. Enfoque intra-sistemático y enfoque extra-sistemático}

Desde hace siglos los juristas han usado pacíficamente el vocablo "antinomia" para referirse a una incompatibilidad (un conflicto) entre dos normas. Lo que en último término implica también la existencia de una imposibilidad práctica: la imposibilidad de adecuar el propio comportamiento a normas entre sí incompatibles o contrastantes ${ }^{28}$. De allí que, desde el punto de vista del sistema jurídico, una antinomia se presenta como una especie de conflicto interno; es decir, como un conflicto intra-sistemático. Desde el punto de vista extra-sistemático, en cambio, los conflictos pueden verse -desde un enfoque de filosofía práctica-como "conflictos prácticos" o-desde un enfoque de filosofía moral (cuando se da el caso)- como "dilemas morales".

Los conflictos prácticos personales suelen ser definidos como aquellos en los que una persona (un agente) posee razones contrastantes para hacer $\mathrm{A}$ o $\mathrm{B}$, sin poder realizar ambas acciones a la vez ${ }^{29}$. Por extensión, se habla de conflictos prácticos interpersonales, para hacer referencia a aquellos conflictos en los que distintos agentes poseen dife-

${ }^{26}$ Chiassoni, P., Técnicas de interpretación jurídica. Breviario para juristas, Madrid, Marcial Pons, 2011, pág. 286 y ss.

${ }^{27}$ Martínez Zorrilla, D., "Conflictos normativos", en Fabra Zamora, J.L., Núñez Vaquero, A., Enciclopedia de Filosofía y Teoría del Derecho, Volumen 2, Ciudad de México, UNAM, 2015, pág. 1324 y ss.

28 Vid., Hart, H.L.A., "Teoría de Kelsen sobre la unidad del derecho", Boletín Mexicano de Derecho Comparado, 21, 1974, pág. 125 y ss.

${ }^{29}$ Cfr.., Raz, J., "Personal Practical Conflicts", en Baumann, P., Betzler, M., (eds.), Practical Conflicts. New Philosophical Essays, Cambridge, Cambridge University Press, 2004, pág. 172 y ss. 
Dilemas morales, conflictos entre derechos y conflictos...

rentes razones para la acción, contrastantes entre ellas ${ }^{30}$. Las personas tienen o aceptan diferentes deseos, preferencias, intereses, objetivos, planes, compromisos, valores, virtudes, obligaciones y normas mora$1 \mathrm{es}^{31}$. Y todos estos pueden conducir a conflictos prácticos, dado que en determinadas circunstancias todos ellos constituyen action-guiding claims $^{32}$. (Las razones involucradas en estos casos son razones para actuar, no para creer $^{33}$ ). En este tipo de razonamientos, dice von Wright, se «entiende a una acción individual de acuerdo al trasfondo de sus razones, i.e., los fines deseados por el agente y los medios que se tienen en cuenta para lograrlos» ${ }^{34}$.

Todos los conflictos prácticos representan especies de conflictos cuya implicación última es que dos conductas no pueden ejercerse simultáneamente, de tal suerte que al generarse, en última instancia, una incompatibilidad práctica, toda antinomia jurídica es también una especie de conflicto práctico, aunque no todo conflicto práctico es también una antinomia jurídica. En el caso de los antinomias entre derechos, y particularmente entre derechos fundamentales, estas especies de conflictos prácticos suelen revestir-según la concepción estándarun valor moral especial, de modo que estos suelen ser más frecuentemente tratados como especies de dilemas morales. Ello, en la medida en que tales conflictos se enfocan en la existencia de moral requirements contrastantes. Por supuesto, también los dilemas morales son especies de conflictos prácticos, de modo que todo dilema moral es asimismo un conflicto práctico, pero no todo conflicto práctico es también un dilema moral. Si un conflicto práctico puede ser entendido -en sentido puramente metafórico-como una "arena de intereses en competición",

${ }^{30}$ En general, sobre los conflictos prácticos, vid., Baumann, P., Betzler, M., (eds.), Practical Conflicts. New Philosophical Essays, Cambridge, Cambridge University Press, 2004.

${ }^{31}$ Ibidem, pág. 1 y ss.

32 Ídem.

33 Dice Celano: «Una ragione è una considerazione che milita (depone) a favore di, o contro, una credenza (ragioni per credere) o un'azione (ragioni per agire)». Celano, B., "La forza dell'argomento migliore", Diritto \& Questioni pubbliche, 9, 2009, pág. 231.

34 von Wright, G.H., "Valor, norma y acción en mis escritos filosóficos. Con un epílogo cartesiano”, Doxa, Cuadernos de filosofía del derecho, 26, 2003, pp. 37-38. 
en el caso de los dilemas morales estos intereses (usando la palabra en sentido lato) toman la forma de exigencias morales que se estiman en conflicto, a veces por parte de un solo agente (dilemas morales personales), a veces por parte de varios agentes (dilemas morales interpersonales) ${ }^{35}$.

\section{Incidencia sobre los derechos y dilemas morales}

Para conectar el punto anterior con lo que diré en lo sucesivo, considero necesario distinguir entre los "derechos reivindicados", los "derechos reconocidos" (por el derecho positivo) y los "derechos protegidos" (por los intérpretes) ${ }^{36}$. En la lucha por los derechos, en esta serie de conflictos arriba descritos, los derechos aparecen desempeñando distintos roles. Por ejemplo, cuando hablamos de los derechos reivindicados, podemos hacer referencia al menos a dos tipos de reivindicaciones distintas: (i) reivindicaciones de lege ferenda, y (ii) reivindicaciones de sententia ferend $a^{37}$. Una reivindicación del primer tipo (reivindicación frente al legislador), es una reivindicación sobre el contenido de la legislación futura; esto es, sobre el contenido de un derecho reconocido. Una reivindicación del segundo tipo (reivindicación frente al juez), es una reivindicación sobre el contenido de una determinada decisión; es decir, sobre el contenido de un derecho protegido por los intérpretes.

En un pasaje de Moral Thinking (1981), Hare dice lo siguiente:

[T]odas las disputas difíciles, como aquella referente a los derechos de las mujeres, surgen en los casos en donde es reivindicado un derecho moral y no un derecho jurídico en sentido estricto. Si la gente que hace campaña por los derechos de las mujeres estuviera pensando en derechos jurídicos existentes, podría acudir a las cortes en lugar de ir a manifestarse; la

35 MacConnell, T., "Interpersonal moral conflicts". American Philosophical Quarterly, 25 (1), 1998, pp. 25-35.

36 Bobbio, N., El tiempo de los derechos, Madrid, Sistema, 1991, pág. 22.

${ }^{37}$ Guastini, R., La sintaxis..., op. cit., pág. 91. 
Dilemas morales, conflictos entre derechos y conflictos...

cuestión, sin embargo, se refiere a aquello que moralmente el derecho debería ser, no a lo que el derecho es ${ }^{38}$.

En realidad, también podrían ir a las cortes, con la esperanza de que un derecho moral reivindicado sea reconocido por los intérpretes (los "jueces") como un derecho jurídico, incluso cuando no lo haya hecho así el legislador. Tal fue el caso, por ejemplo, de Obergefell $v$. Hodges (2015) de la Corte Suprema de los Estados Unidos, donde se reconoció el derecho de las parejas homosexuales a contraer matrimonio legal en todo el territorio de ese país. Sin embargo, se entiende perfectamente el objetivo al que apunta Hare; esto es, que la investigación acerca de qué cuenta como un derecho jurídico en un determinado sistema es diferente de aquella sobre qué debería contar como tal.

Los derechos reivindicados son, en general, "derechos morales"; es decir, derechos que apelan a una determinada moral -a cierto sistema moral ${ }^{39}$ - que se estima como justificación suficiente para lograr también su reconocimiento legislativo o su protección judicial. En otras palabras, se conviene que el derecho, o bien no ha reconocido una determinada potestad, pretensión, etc., o bien ha prohibido su ejercicio; pero se pide que este estado de cosas sea cambiado. Por supuesto, a veces se reivindican "derechos morales" en contextos no jurídicos ${ }^{40}$, aunque es usual que lo contrario suceda con determinadas reivindicaciones, como en el caso de ciertos derechos de las mujeres, de los homosexuales o de las minorías étnicas. Los conflictos entre derechos reivindicados, al nivel de los juegos cooperativos ("conflictos por la constitución o la legislación"), propios de la discusión parlamentaria, se traducen frecuentemete en la confrontación de diversos planes políticos e ideológicos. La "pelea" por el establecimiento de ciertas disposiciones, de acuerdo a un ideario, como "derechos subjetivos (fundamentales)" tiene como objetivo su reconocimiento constitucional o

${ }^{38}$ Hare, R.M., Moral Thinking. Its Levels, Method, and Point, Oxford, Clarendon Press, 1981, pág. 150.

39 Vid., Guastini, R., Distinguiendo, Barcelona, Gedisa, 1999, pp. 181-182.

40 Vid., Hart, H.L.A., Essays on Bentham. Studies in Jurisprudence and Political Theory. Oxford: Clarendon Press, 1982, pág. 82 y ss. 
legal. Esta determinación inicial, empero, no garantiza el contenido final de las normas interpretadas a partir de tales disposiciones ${ }^{41}$. Los juegos no-cooperativos ("conflictos en la constitución o la legislación") de las partes procesales, tienen como fin determinar el contenido de un derecho protegido (por los intérpretes). De tal suerte que distintos tipos de conflictos pueden producir resultados diferentes, y las interacciones que se producen pueden implicar, a su vez, posiciones diversas acerca del contenido del derecho. En el derecho se dan conflictos, pero también estos conflictos hacen al derecho. Con esto quiero decir, simplemente, que su resolución define, en último término, aquello que ha de contar como derecho en tal o cual ordenamiento jurídico (el aspecto nomodinámico del derecho es ineludible ${ }^{42}$ ).

Por supuesto, en estos casos hay espacio para hablar de posibles dilemas morales. Piénsese, por ejemplo, en una discusión parlamentaria acerca de la eutanasia o el aborto. Es de esperar que en este caso nos encontremos con un dilema moral. ¿Pero de qué tipo? Se trata, como parece obvio, de un dilema moral interpersonal; es decir, como ya se vio, un conflicto en el que concurren varios agentes cuyas posiciones morales son divergentes (agentes que, de paso, podrían no ver su propia posición individual como dilemática ${ }^{43}$ ); de tal manera que el conflicto moral surge, justamente, por el encuentro de diversas "morales": de diversos "sistemas morales". Otro tanto puede decirse sobre los conflictos judiciales en los que se discuten asuntos de esta envergadura. Es de esperar que las partes procesales en conflicto defiendan también diferentes posiciones morales acerca de temas diversos. Por supuesto, también en este caso es posible que cada una de las partes no vea su

${ }^{41}$ Basta ver las diferencias entre los fallos Bazterrica (1986), Montalvo (1990) y Arriola (2009), de la Corte Suprema de Justicia de la Nación argentina, respecto a la tenencia de marihuana para consumo personal (todos bajo la vigencia del artículo 19 de la Constitución).

42 En general, vid., Celano, B., Derecho..., op. cit., pág. 23- 59; 145; 151-169; pág. 281-299.

43 MacIntyre, por ejemplo, dice que es habitual hablar de dilemas morales (por ejemplo, en la tragedia griega), allí en donde, en varias ocasiones, no se puede decir que los propios implicados hayan visto su situación como dilemática. MacIntyre, A., "Moral Dilemmas", Philosophy and Phenomenological Research, 50, 1990, pp. 367-382. 
Dilemas morales, conflictos entre derechos y conflictos...

propia posición moral como el producto de un dilema; al contrario, el dilema (interpersonal) se produce en la medida en que dos partes diferentes sostengan, verbigracia, que el aborto debería estar permitido, por un lado, y que debería estar prohibido, por otro. Cualquier resultado sacrificará algo valioso para una de las partes. En este caso, un conflicto entre derechos reivindicados coincide con el contenido de un dilema moral interpersonal. Aunque quizás sería más preciso decir que es la existencia del dilema moral interpersonal la que crea, a menudo, el conflicto jurídico (cooperativo o no-cooperativo).

Cuando hablamos de un sistema normativo, sea éste moral o jurídico, hacemos referencia a -usando la conocida expresión bobbianaun "conjunto estructurado de normas" 44 . La diferencia entre unos y otros es, à la Kelsen, que los sistemas jurídicos son sistemas dinámicos, mientras que los sistemas morales son sistemas estáticos. Tanto en los sistemas morales como en los sistemas jurídicos se pueden presentar conflictos o dilemas que, vistos desde el punto de vista de cada uno de esos sistemas, son conflictos normativos intra-sistemáticos. Sea que se trate de la moral positiva (o social), sea que se trate de la moral crítica (esto es, de la moral compartida por un grupo específico: la moral cristiana, la moral marxista, la moral liberal, etc. ${ }^{45}$ ), es posible que nos encontremos con diferentes conflictos, sean personales, sean interpersonales. Se trata, en ambos casos, de una "disputa" normativa; es decir, del conflicto entre normas o reglas de conducta incompatibles que serían aplicables a un mismo caso moral, en donde las opciones a disposición son excluyentes y no son indiferentes (en el caso de los dilemas morales "auténticos"). Ahora bien, tanto un dilema moral personal como un dilema moral interpersonal pueden ser el producto del encuentro no de un solo sistema moral, sino de varios sistemas morales "en competición": la moral cristiana y la moral liberal en materia del aborto o la eutanasia, por ejemplo.

${ }^{44}$ Bobbio, N., Teoria generale del diritto, Torino, Giappichelli, 1993,pág.8. Vid., para un desarrollo de este punto en específico, Guastini, R., "Insiemi strutturati di norme. Contributi di Bobbio alla teoria dei sistemi normativi", Analisi e Diritto, 2004, pp. 103-117.

45 Vid., Guastini, R., Distinguiendo..., op. cit., pp. 181-182. 
Mauricio Maldonado Muñoz

Creo que, mutatis mutandis, esto último va en la línea de la crítica de Rivera López a Martínez Zorrilla:

[L]a restricción que establece Martínez en la definición de "dilema moral", según la cual se trata de un conflicto que ocurre dentro de un mismo sistema moral, puede ser peligrosamente circular, si es que se define sistema moral como algo necesariamente coherente... [L]a idea de que puede haber dilemas morales apunta, creo, a que quizá no podamos reunir todas nuestras convicciones morales dentro de un mismo sistema. Diferentes convicciones que entran en pugna obedecen a diferentes sistemas morales que conviven dentro del cuerpo de creencias morales de un agente $e^{46}$.

Si esto último es correcto, entonces un dilema moral personal puede ser, sin duda, el producto del encuentro de varios sistemas morales. Sin embargo de todo esto, Martínez Zorrilla rechaza que se puedan dar "verdaderos" dilemas en el marco de varios sistemas normativos en competición: un dilema -dice él-sólo puede presentarse al interior de un único sistema normativo ${ }^{47}$.

Como bien señala Lariguet, Martínez Zorrilla deja fuera «situaciones en que diversos sistemas morales alternativos ofrecen soluciones divergentes e incompatibles» ${ }^{48}$. En la respuesta a los participantes, Martínez Zorrilla pretende defenderse de esta crítica, aunque sin demasiado éxito ${ }^{49}$. Creo que en esta parte Lariguet da en el blanco: «un desafío para los filósofos es que logremos distinguir, para el caso del derecho, las distintas y más relevantes situaciones dilemáticas y

\footnotetext{
${ }^{46}$ Rivera López, E., "Dilemas morales...”, op. cit., pág. 112. El énfasis es añadido.

${ }^{47}$ Martínez Zorrilla, D., "Dilemas morales...”, op. cit., pág. 20.

${ }^{48}$ Lariguet, G., "Dilemas morales...", op. cit., pág. 60.

49 Dice Martínez Zorrilla: «me parece algo evidente que el concepto de conflicto/ dilema se circunscribe a un sistema normativo, ya que una colisión entre normas sólo puede plantearse dentro de los límites de un conjunto de normas. Los límites de ese conjunto determinan el sistema normativo de referencia». Martínez Zorrilla, D., "Respuestas...", op. cit., pág. 145. Como se verá enseguida, las cosas no parecen ser exactamente de este modo.
} 
Dilemas morales, conflictos entre derechos y conflictos...

no encasillarnos en una como hace Martínez» ${ }^{50}$. Si un dilema moral que es el producto del encuentro de varios sistemas morales es posible (tanto a nivel personal como interpersonal), y la fenomenología de los dilemas morales así lo sugiere, entonces dejarlos fuera deja de lado un aspecto importante: una pieza faltante en un rompecabezas hecho de piezas diferentes. Los dilemas morales interpersonales, de hecho, pueden resultar mucho más relevantes para el derecho que los dilemas personales. Basta considerar que el derecho está indisolublemente asociado al fenómeno de la alteridad (ubi societas ibi ius), y por ello no suele enfocarse en los conflictos subjetivos, sino en los conflictos intersubjetivos.

¿Pero hay espacio en el derecho para los dilemas morales personales? Una respuesta posible es la siguiente: podríamos hablar de este tipo de dilemas cuando un juez deba decidir ciertos problemas en los que él entienda implicadas decisiones morales para las que posee razones contrastantes que "militan" a favor de dos cursos de acción distintos. Podríamos decir, sin duda, que del mismo modo en que en un contexto extra-jurídico un agente puede verse inmerso entre dos opciones que le plantean un dilema, también un juez puede verse abocado a la pregunta añosa: “iqué curso de acción no produce males?”. Pero también aquí hemos de presumir que el juez del ejemplo ha asumido su propia decisión como dilemática, al menos desde el punto de vista moral, aunque ello no sea necesariamente así. Bien podríamos estar ante un juez conservador que no tiene dudas acerca de la inmoralidad del aborto o de la eutanasia, para mencionar los dos ejemplos que ya he usado ${ }^{51}$.

${ }^{50}$ Lariguet, G., "Dilemas morales...", op. cit., pág. 60.

${ }^{51}$ Que las posiciones morales de los jueces pueden llegar, en ciertos casos, a determinar el contenido del derecho, es una afirmación que, hoy por hoy, a pocos sorprende. Dice, por ejemplo, Bobbio: «esempi che tutti quanti abbiamo sott'occhio e che sono stati anche raccolti da pubblicazioni recenti sui giudizi di valore dei giudici, riguardo al l'esistenza di sentenze diverse e anche talora ripugnanti tra loro, soprattutto in materie politicamente incandescenti, come lo sciopero, la serrata, e in genere le libertà civili. (Esempi, vorrei dire tra parentesi, che sono scandalosi non perché mostrano che il giudice non è, come pretende di essere, nelle raffigurazioni agiografiche delle cerimonie ufficiali, apolitico, ma perché la sua politica è nella maggior parte dei casi 
Por lo demás, nótese que un dilema moral no puede disociarse de las razones de un agente o varios para hacer A o B. Pero debe decirse también que el hecho de que una situación de dilema se plantee como tal supone frecuentemente el concurso de diferentes posibilidades prácticas, no solo normativas. Piénsese, de hecho, que una buena parte de los dilemas morales que suelen plantearse constituyen casos de incompatibilidad en concreto. Por ello, muchas veces el dilema no es la consecuencia, en sí, de una "falla" en el/los sistema(s) moral(es), sino más bien, por decirlo de alguna manera, de una "falla" en el mundo: del hecho de que, en determinadas circunstancias, no sea posible-desde el punto de vista práctico- seguir dos directivas que no se oponen necesariamente ${ }^{52}$.

\section{Conflictos ("genuinos" o "aparentes") entre derechos}

El debate entre los conflictivistas y los anti-conflictivistas en el marco de los derechos fundamentales; esto es, el debate entre quienes sostienen que se dan "verdaderos" (o "genuinos") conflictos entre derechos y aquellos que lo niegan, no constituye, como suele aparecer a ojo de buen cubero, una discusión unidimensional que admite, pura y simplemente, respuestas absolutas. Por el contrario, se trata de una serie de debates multidimensionales y, hasta cierto punto, heterogéneos. Más aún, la contraposición entre las posiciones conflictivistas y anti-conflictivistas, no siendo unívoca e unidimensional (siendo heterogénea y multidimensional), no corresponde, tampoco, a una serie de posicio-

una politica sordamente conservatrice, e spesso anche anticostituzionale)». Bobbio, N., "Quale giustizia, quale legge, quale giudice", Quale giustizia, 2 (8), pág. 270.

${ }^{52} \mathrm{Tal}$ como no se oponen, en el ejemplo que usé al inicio de este trabajo, la norma que exige a Orestes vengar la muerte de sus padres y la que le exige respetarlos. Guastini rememora este ejemplo señalando, justamente, que se trata de una antinomia en concreto: «Non vi è antinomia in astratto tra la norma che obbliga a vendicare i genitori e quella che impone di rispettarli. L'antinomia nasce in concreto dalla circostanza, accidentale, che l'assassino di Agamennone è appunto Clitennestra». Guastini, R., Interpretare e argomentare, Milano, Giuffrè, 2011, pág. 107. 
Dilemas morales, conflictos entre derechos y conflictos...

nes necesariamente consistentes o coherentes entre ellas ${ }^{53}$. De alguna manera, lo dice también Comanducci:

A la pregunta: "¿existe compatibilidad o incompatibilidad entre derechos fundamentales?", se puede dar respuestas diversas, y no necesariamente incompatibles entre ellas, según el nivel de análisis que se escoja, según las definiciones que se usen de "derechos fundamentales", y también según lo que se entienda por (in)compatibilidad ${ }^{54}$.

En la discusión en cuestión, de hecho, podemos encontrar varios debates que incluyen a su vez posiciones diferentes acerca de varios aspectos distintos sobre los derechos. Algunos de estos debates son los siguientes: (1) la problemática sobre los límites de los derechos desde dos teorías enfrentadas: la teoría de los límites externos (asociada generalmente al conflictivismo), y la de los límites internos de los derechos fundamentales (asociada al anti-conflictivismo); (2) el debate entre la teoría especificacionista, en virtud de la cual los derechos no colisionan siempre que sean suficientemente especificados, y la teoría infraccionista, que sostiene que en ciertos casos la "infracción" de un derecho no implica su "violación" (la primera anti-conflictivista, la segunda conflictivista); (3) la discusión entre la teoría del pluralismo de los valores y el monismo ético (la última anti-conflictivista, la primera

${ }^{53}$ En general, sobre el debate en cuestión, vid., Maldonado Muñoz, M., "Conflictivismo y anti-conflictivismo en los derechos fundamentales", Diritto \& Questioni pubbliche, 16 (2), 2016, pág. 105-131. Cito una parte de la bibliografía relevante, además de la ya citada en el marco de la discusión entre el especificacionismo y el infraccionismo (vid., nota 10): Waldron, J., "Rights in conflict", Ethics, 99 (3), 1989, pág. 503-519. Bin, R., "Diritti e fraintendimenti", Ragion Pratica, 14, 2000, pág. 15-25. Alexy, R., "Constitutional Rights, Balance, and Rationality", Ratio Iuris, 16, 2003, pág. 131-140. Marmor, A., "On the Limits of Rights", Law and Philosophy, 16, 1997, pág. 1-18. Celano, B., "Come deve essere la disciplina costituzionale dei diritti?", en S. Pozzolo (a cura di), La legge e i diritti, Torino, Giappichelli, 2002, pág. 89-123. Ferrajoli, L., "I fondamenti dei diritti fondamentali", Teoria politica, 16 (6), 2000, pág. 41-113. Pino, G., "Conflictos entre derechos fundamentales. Una crítica a Luigi Ferrajoli", Doxa, 32, 2009, pág. 649-650.

${ }^{54}$ Comanducci, P., "Problemi di compatibilità tra diritti fondamentali", Analisi e Diritto, 2002-2003, pp. 317-318. 
conflictivista); (4) la discusión entre la teoría coherentista y aquella no-coherentista (anti-conflictivista y conflictivista, respectivamente) ${ }^{55}$. Como apunta Comanducci, una de las razones por las que se produce esta discusión del todo variopinta es que los distintos teóricos usan -casi siempre sin hacerlo explícito- distintos conceptos de "derechos fundamentales", pertenecientes a niveles de análisis distintos entre sí; a la vez que suelen usar -muy frecuentemente, de hecho- conceptos distintos de "conflicto". Como se vio hasta ahora, diferentes tipos de conflictos pueden ser identificados en el marco del derecho. Y embargo, la idea de que no se dan conflictos entre derechos se resiste a ser borrada del mapa. A pesar de las apariencias, ¿cómo es posible sostener que no se dan conflictos "genuinos" entre derechos?

Resulta oportuno, en este punto, acudir a la posición de Martínez Zorrilla acerca de la posibilidad de que se presenten o no dilemas morales "genuinos". Esta posición, mutatis mutandis, se puede aplicar al debate entre conflictivistas y anti-conflictivistas. Creo que en esta parte Martínez Zorrilla da en el clavo. Efectivamente, en la respuesta a los participantes recalca que su posición trae sus huellas, en buena parte, en la teoría de Zimmerman, quien -a diferencia de nuestro autor- no admite la posibilidad de que se den "verdaderos" dilemas. En esta divergencia, Martínez Zorrilla apunta lo siguiente:

Es cierto que yo adopto las nociones de "obligación moral" y "permisión moral" de Zimmerman, y que desde el punto de vista de este autor no son posibles los dilemas, ya que parte de la noción de obligación definitiva (overall o all things considered), y por razones lógicas no puede haber dos obligaciones definitivas incompatibles... Pero lo que cambia entre Zimmerman y yo es que yo no utilizo el mismo concepto de "dilema" que este autor, sino que mi concepto es, en suma, el de "conflicto entre obligaciones no superadas", esto es, el de la indeterminación del curso moralmente obligatorio (no existe obligación definitiva) ${ }^{56}$. 
Dilemas morales, conflictos entre derechos y conflictos...

Lo dice también, de algún modo, cuando habla de las posiciones divergentes de Conee ${ }^{57}$ (para quien un dilema es un conflicto entre obligaciones definitivas) y Sinnot-Armstrong ${ }^{58}$ (para quien un dilema es un conflicto entre obligaciones no vencidas). Para el primer autor, los dilemas son conceptualmente imposibles, para el segundo no ${ }^{59}$. Es justamente esta divergencia la que hace que en ciertos casos "aparezcan" dilemas genuinos y en otros no. Sin embargo, lejos de realizar las distinciones del caso -como dice el propio Martínez Zorrilla- muchos autores simplemente persisten en sus propias posiciones, «dando a entender que sus diferencias son más profundas de lo que en realidad son $»^{60}$.

Es fácil ver por qué en el caso del debate entre conflictivistas y anti-conflictivistas se puede llegar a conclusiones similares. Piénsese, por ejemplo, en el debate entre los especificacionistas y los infraccionistas. Los especificacionistas tratan a los derechos, en general, como "derechos absolutos"; mientras que los infraccionistas los tratan como "derechos pro-tanto"61. Los especificacionistas, obligados a encontrar las cláusulas exceptivas que les permitan llegar a especificaciones no conflictivas, tratan a los derechos como puntos de arribo finales. De tal suerte que la persistencia de un conflicto aparece como el producto de una "mala" o "incompleta" especificación. Los infraccionistas, condenados a encontrar los casos de infracción, tratan a los derechos, en términos de -diría Martínez Zorrilla- "razones no superadas", de modo que los conflictos se presentan como fenómenos más o menos comunes. Y algo similar se podría decir, por ejemplo, sobre el debate entre coherentistas y no-coherentistas, o el debate entre los defensores de la teoría de los límites externos y la teoría de los límites internos:

57 Vid., Conee, E., "Against Moral Dilemmas", The Philosophical Review, 91 (1), 1982, pp. 87-97.

58 Vid., Sinnott-Armstrong, W., "Moral Dilemmas and Incomparability", American Philosophical Quarterly, 22 (4), 1985, pp. 321-329.

${ }^{59}$ Martínez Zorrilla, D., "Respuestas...”, op. cit., pág. 149.

${ }^{60}$ Ibidem, pág. 150.

${ }^{61}$ Vid., v.gr., Wellman, C.H., "On Conflicts...", op. cit. Shafer-Landau, R., "Specifying...", op. cit. Oberdiek, J., "Lost in moral...", op. cit. Botterell, A., "In defence...", op. cit., Thomson, J.J., "Some ruminations...", op. cit. Frederick, D., "Pro-tanto versus absolute rights", The Philosophical Forum, 2014, pp. 375-374. 
unos tratan a los derechos, en general, como derechos prima facie; los otros, como derechos all things considered ${ }^{62}$.

Si retomamos la distinción, con pretensiones descriptivas, entre los derechos reivindicados, los derechos reconocidos, y los derechos protegidos por los intérpretes, en cada uno de estos casos el "derecho" del que se hable corresponderá a una cierta conducta que opera a diferentes niveles (por lo que estos no serán, al mismo nivel, "derechos"). Los derechos reivindicados; esto es, en general, los derechos morales, suelen encontrarse frecuentemente en conflicto entre ellos: aquí el conflicto puede asumir la forma de un conflicto práctico o de un dilema moral (aunque puede tratarse de un simple conflicto valorativo o de una forma de desacuerdo). En el caso de los derechos reconocidos; esto es, de las pretensiones justificadas (en normas positivas), se puede decir que el conflicto asume generalmente la forma de una antinomia jurídica. En el caso de los derechos reconocidos por los intérpretes; esto es, de las pretensiones protegidas o tuteladas por los jueces, se puede decir que en último término no se dan conflictos entre los derechos, al menos en los casos puntuales en los que un derecho efectivamente tutelado está atado a la decisión final de un problema jurídico. En este último caso los derechos no se encuentran entre las premisas de un razonamiento, sino que constituyen su conclusión, de modo que de "derechos" se hablaría sólo después de la interpretación (auténtica) final realizada por los intérpretes, no antes. Esto último resulta conceptualmente viable, aunque en cierto sentido banal para el desarrollo del debate. De estos breves apuntes se puede extraer una conclusión con fines heurísticos: los derechos están (a veces) en conflicto entre ellos si se hallan entre las premisas de un razonamiento, y no lo están (en general) si son el resultado final de éste. Todo esto, claro está, con independencia de su contenido ${ }^{63}$. Esto último es, según creo, lo que tienen en común las teorías anti-conflictivistas, sea en materia de dilemas, sea en materia de conflictos. Creo que la distinción de Martínez Zorrilla abona también a esta conclusión. 
Dilemas morales, conflictos entre derechos y conflictos...

\section{Dilemas morales y conflictos entre derechos}

Como ya he dicho, me parece que es irrecusable señalar que podemos identificar la presencia de determinados dilemas morales en el marco de los conflictos entre derechos reivindicados. Sin embargo, se plantea si también en el marco de los derechos reconocidos (por el derecho positivo) se puede hablar de dilemas morales. Como ya señalé, esto tiene que ver con dos puntos de vista distintos: uno intra-sistemático y otro extra-sistemático. Por supuesto, el contenido del conflicto jurídico y del dilema moral podrían coincidir (i.e., el conflicto intra-sistemático y el conflicto extra-sistemático podrían corresponderse), pero no es necesario que esto ocurra. Aquí Martínez Zorrilla vuelve a acertar: no todo caso de dilema moral es también un caso de conflicto constitucional (de conflicto entre derechos, o entre derechos y bienes públicos), ni viceversa.

Téngase en cuenta que la premisa de esta distinción es la vieja tesis positivista de la separación entre el derecho y la moral. Tesis compartida por Martínez Zorrilla ${ }^{64}$, y a la que yo también me inclino. Señalar que los conflictos o los dilemas morales coincidan siempre con las antinomias presentes en un sistema jurídico, particularmente en materia de derechos, deja de lado la distinción entre los "derechos morales" y los "derechos jurídicos". Lo cual puede crear, como dice Barberis, no solo problemas teóricos, sino también problemas prácticos. Por lo demás, distinguir entre lo que cuenta como un derecho jurídico y lo que debería contar como tal, permite diferenciar el derecho "que es", del derecho que "debe ser": tesis compartida por todos los positivistas ${ }^{65}$.

${ }^{64}$ Martínez Zorrilla, D., “Respuesta...”, op. cit., pág. 147.

${ }^{65}$ Como bien señala Barberis, cuando se pregunta si el derecho a la desobediencia civil es solo moral o es también jurídico, en el fondo se pregunta si ejerciéndolo se corre el riesgo o no de terminar en la cárcel. Vid., Barberis, M., Ética..., pág.15. Para decirlo de otra manera, e ilustrarlo con otro ejemplo, a una pregunta del tipo, "jjurídicamente los homosexuales tienen derecho a contraer matrimonio?", se puede responder simplemente: "depende" (en el ordenamiento jurídico estadounidense sí, en el peruano no, en el argentino sí, en el ecuatoriano no, y así por el estilo). En cambio, el enfoque varía si la pregunta es "¿deberían o no poder contraer matrimonio legal las parejas homosexuales?”. El primer caso supone la existencia o no de un derecho jurídico, el segundo, la existencia o no de un derecho moral. Por supuesto, aquí también podemos hallar dife-

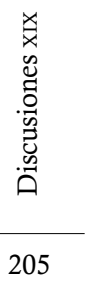


Estos apuntes tienen mucha relevancia en la medida en que, en el marco de la discusión entre conflictivistas y anti-conflictivistas, también encontramos a aquellos que de un plumazo confunden todas las categorías en un único tipo de conflicto (quizás de modo preterintencional, si uno quiere hacer una interpretación caritativa). Es el caso, por ejemplo, de algunos pluralistas ${ }^{66}$. Para ellos, la cuestión pasa por la afirmación de la heterogeneidad de los valores, de los deseos y de las metas de los distintos individuos: en general, de sus diversos planes de vida y de las diferentes concepciones sobre el "bien". Se afirma que esta es una característica de las sociedades occidentales contemporáneas; las que serían, por esto, individualistas (no organicistas). Las personas, en los Estados contemporáneos -según la concepción liberal-, tienen el derecho al libre desarrollo de su personalidad y a elegir libremente su plan de vida, y está claro que en un entorno de ese tipo se producen conflictos entre los distintos ideales de vida. Para los pluralistas, esto supone también la existencia de conflictos entre los diferentes derechos (fundamentales) en el propio derecho. Sin embargo, ¿los conflictos entre valores implican, necesariamente, los conflictos entre derechos jurídicos? O bien, cuando hablamos de conflictos entre valores, entre concepciones del bien, entre planes de vida diferentes, etc., ¿hablamos también de conflictos entre derechos? A primera vista se podría decir que sí: los ordenamientos jurídicos actuales, cuya inspiración -en cuanto hijos de la concepción liberal- se reconduce al pluralismo, aceptan el conflicto como un fenómeno fisiológico (no patológico), en ausencia del cual no se podría dar aquello que Bobbio llamaba fecundidad del antagonismo ${ }^{67}$. Visto esto, se podría decir que también entre derechos fundamentales se dan estos mismos conflictos. Estas observaciones, en principio incontestables, crean, sin embargo,

rentes respuestas dependiendo del sistema moral de referencia que elijamos privilegiar. Por lo demás, tanto un sistema jurídico como un sistema moral podrían ofrecer posibles respuestas incompatibles a este tipo de problemas, o podría darse que distintos sistemas morales resulten también incompatibles al momento de ofrecer soluciones a un dilema moral interpersonal.

${ }^{66}$ Ibidem, pág. 111 y ss.

${ }^{67}$ Bobbio, N. Liberalismo y democracia, Bogotá, Fondo de Cultura Económica, 2013. 
Dilemas morales, conflictos entre derechos y conflictos...

una inquietud ulterior: ¿está la analogía bien construida (es necesaria)? Mi respuesta es que no: una cosa son los conflictos entre valores, los dilemas morales y los conflictos prácticos y otra cosa son los conflictos entre derechos (al menos si queremos distinguir los conflictos entre derechos reivindicados y los conflictos entre derechos reconocidos).

En esta sede basta decir que los casos referentes a derechos no son reducibles ni a los conflictos prácticos ni a los dilemas morales, como tampoco a los conflictos valorativos en general: hay muchos conflictos (prácticos, morales, valorativos) que nada tienen que ver con los derechos, así como hay conflictos entre derechos jurídicos que raramente crearían -a ojos de un moralista-dilemas "genuinos". Más aún, se suele considerar que los derechos jurídicos son independientes de nuestras valoraciones morales particulares: v.gr., en un ordenamiento jurídico en donde se considere al aborto (en ciertos casos, dadas ciertas condiciones) como un derecho, tal ha de considerarse de ese modo (para ese ordenamiento) con independencia del acuerdo o desacuerdo moral sobre la cuestión. Y esto sin negar que en un caso como éste se presenta un conflicto práctico, un dilema moral o un conflicto valorativo que persiste a la resolución jurídica del conflicto. (Sería, de hecho, muy peligroso para la moral que el derecho se atribuyese la autoridad final para poder resolver o disolver los dilemas morales o los conflictos valorativos de modo definitivo). Cuando en Roe v. Wade (1973) la Corte Suprema de los Estados Unidos de América dice: «nuestra tarea es resolver la cuestión desde criterios constitucionales, al margen de las inclinaciones personales y de las pasiones», dice que el conflicto moral persistirá fatalmente, aunque no, como es obvio, el conflicto jurídico. En suma, cuando los pluralistas hablan de "conflicto entre derechos", ¿a qué conflictos se refieren? Está claro que desde el punto de vista moral somos diversos (poseemos concepciones diferentes sobre el bien); aunque, desde el punto de vista estrictamente jurídico, la "calificación" de una determinada conducta como "derecho" depende -en términos generales- de la determinación de su contenido mediante el ejercicio de los poderes de producción y aplicación del derecho ${ }^{68}$.

68 Vid., Celano, B., "Derechos fundamentales y poderes de determinación en el estado constitucional de derecho", en B. Celano, Derecho..., op. cit., pp. 281-298. 
Nadie duda, por ejemplo, que en un caso sobre tortura en el que se busque que un terrorista revele la ubicación de una bomba, se encuentra en juego la integridad física del presunto terrorista así como la integridad personal y la vida de muchas personas (además del dilema moral que afrontará el agente sobre la admisibilidad de torturarlo o no). Pero, aun así, en la mayoría de los ordenamientos contemporáneos la prohibición de la tortura es absoluta (independiente absolutamente de todas nuestras valoraciones morales o de los casos) e inderrotable (no sujeta a excepciones implícitas o explícitas). Para el enfoque específicamente jurídico (en los ordenamientos donde así se prevea), este constituye un derecho pleno: el derecho del terrorista a no ser torturado. Esto no anula o no disuelve el conflicto moral que se produce sobre la admisibilidad o no de la tortura: intuitivamente se podría decir que estaríamos moralmente justificados si decidimos torturar al presunto terrorista porque podríamos salvar la vida de -por hipótesis- miles de personas inocentes. En este sentido, la respuesta a la pregunta: "¿estamos autorizados a torturar a alguien en estas condiciones?", produciría un resultado que algunos encontrarían contradictorio: moralmente sí, jurídicamente no. Por supuesto, siempre que el sistema jurídico de referencia considere la prohibición de la tortura como una norma inderrotable. La administración Bush, por ejemplo, demostró que este aspecto, que parecía consolidado entre los países occidentales, puede estar en entredicho también en el marco del derecho ${ }^{69}$.

En todo caso, en general el dilema moral sobre la cuestión sub$\operatorname{siste}^{70}$, aunque jurídicamente resulte, al menos en la mayoría de ordenamientos, inderrotable (y por ende no enfrentado a otras reglas o principios). Este es, sin embargo, sólo un caso: la mayoría de las normas (también las que tienen que ver con derechos) se consideran -en los ordenamientos jurídicos contemporáneos- derrotables. En tales casos, el conflicto entre valores -así como los dilemas morales o con-

${ }^{69}$ Debo este apunte a uno de los pares revisores de la revista.

${ }^{70}$ Vid., por ejemplo, Moore, M.S., "Torture and the Balance of Evils", Israel Law Review, 23, 1989, pág. 280-344; y La Torre, M., "La Giustizia della Tortura. Variazioni sul tema", Materiali per una storia della cultura giuridica, 1, 2014, pp. 3-29. 
Dilemas morales, conflictos entre derechos y conflictos...

flictos prácticos- se considera como equivalente a los conflictos entre derechos (si por derecho se entiende no ya una conducta determinada reconocida por el derecho, sino un valor, una opción valorativa, etc.), pero esta equiparación, como se ha visto, no es necesaria: bien pueden darse normas jurídicas antinómicas que correspondan a otros tantos derechos, y puede haber derechos que, aun en conflicto con determinadas visiones morales, no tengan (en ese sistema) relaciones antinómicas con otras normas. Que los dilemas morales y los conflictos entre derechos coincidan o no es del todo contingente.

\section{Colofón}

En este trabajo me he propuesto proveer una posible reconstrucción del problema de los dilemas morales y los conflictos entre derechos, con énfasis en el ámbito del derecho, partiendo de un marco que busca identificar los distintos casos de conflicto que se pueden identificar "por" y "en" el derecho. Allí se puede ver cómo, en diferentes circunstancias, diversos escenarios aparecen como dilemáticos. Si no me engaño, esta especie de esquematización constituye un punto de partida interesante para resolver o disolver algunos problemas artificiales, a la vez que provee respuestas para otros problemas persistentes. Como se ha visto, en este camino algunas tesis cardinales de Martínez Zorrilla han resultado de mucha importancia, aunque también he optado por argumentar en contra de otra de sus tesis centrales.

Por lo demás, la discusión acerca de los dilemas morales y los conflictos constitucionales sigue vigente ${ }^{71}$. Y es de esperar que esta situación persista. A fin de cuentas, como dice el poeta, no tiene fin la esperanzadora posibilidad de elegir en nuestras encrucijadas.

${ }^{71}$ Para muestra, un botón. Hace pocos meses se publicó un libro muy interesante de Damiano Canale al respecto: Canale, D., Conflitti pratici. Quando il diritto diventa immorale, Roma-Bari, Laterza, 2017. 


\section{Bibliografía}

Alexy, R., "Constitutional Rights, Balance, and Rationality", Ratio Iuris, 16, 2003, pág.131- 140.

Atienza, M., "Los límites de la interpretación constitucional. De nuevo sobre los casos trágicos", Isonomía, 6, 1997, pág.7-30.

Atienza, M., "Diez preguntas a Martínez Zorrilla", Discusiones, 8, 2008, pág.129-133.

Barberis, M., Ética para juristas, Madrid, Trotta, 2008.

Baumann, P., Betzler, M. (eds.), Practical Conflicts. New Philosophical Essays, Cambridge, Cambridge University Press, 2004.

Bin, R., "Diritti e fraintendimenti", Ragion Pratica, 14, 2000, pág.15-25.

Bin, R., "Che cos'è la costituzione?", Quaderni costituzionali, 1, 2007, pág.11-52.

Botterell, A., "In Defense of Infringement", Law and Philosophy, 27, 2008, pág.269-292.

Bobbio, N., "Formalismo giuridico e formalismo etico", Rivista di Filosofia, 1954, pág.257- 258.

Bobbio, N., "Quale giustizia, quale legge, quale giudice", Quale giustizia, 2 (8), 1975, pág.268-274.

Bobbio, N., El tiempo de los derechos, Madrid, Sistema, 1991.

Bobbio, N., Teoria generale del diritto, Torino, Giappichelli, 1993.

Bobbio, N., Liberalismo y democracia, Bogotá, Fondo de Cultura Económica, 2013.

Broziek, B., "Sobre tû-tû", Revus, 27, 2015, pág.25-34.

Canale, D., Conflitti pratici. Quando il diritto diventa immorale, RomaBari, Laterza, 2017.

Carter, L. \& Burke, T., Reason in Law, Chicago, The University of Chicago Press, 2016.

Celano, B., "Come deve essere la disciplina costituzionale dei diritti?", en S. Pozzolo (a cura di), La legge e i diritti, Torino, Giappichelli, 2002, pág.89-123.

Celano, B., "Justicia procedimental pura y teoría del derecho", en Celano, B., Derecho, justicia, razones, Madrid, Centro de Estudios Políticos y Constitucionales, 2009. 
Dilemas morales, conflictos entre derechos y conflictos...

Celano, B., "El razonamiento jurídico: tres temas clave y lo que la filosofía puede (o no puede) hacer acerca de ellos", en Celano, B., Derecho, justicia, razones, Madrid, Centro de Estudios Políticos y Constitucionales, 2009.

Celano, B., "Derechos fundamentales y poderes de determinación en el estado constitucional de derecho", en Celano, B., Derecho, justicia, razones, Madrid, Centro de Estudios Políticos y Constitucionales, 2009.

Celano, B., "La forza dell'argomento migliore", Diritto \& Questioni pubbliche, 9, 2009, pág.229-255.

Celano, B., Due problemi aperti dell'interpretazione giuridica, Módena, Mucchi, 2017.

Chiassoni, P., Técnicas de interpretación jurídica. Breviario para juristas, Madrid, Marcial Pons, 2011.

Comanducci, P., "Problemi di compatibilità tra diritti fondamentali", Analisi e Diritto, 2002- 2003, pág.317-318.

Conee, E., "Against Moral Dilemmas", The Philosophical Review, 91 (1), 1982, pág.87-97.

Feinberg, J., "Voluntary Euthanasia and the Inalienable Right to Life", Philosophy \& Public Affairs, 7 (2), 1978, pág.93-123.

Ferrajoli, L., "I fondamenti dei diritti fondamentali", Teoria Politica, 16 (6), 2000, pág.41- 113.

Finkelstein, C.O., "Two Men And A Plank", Legal Theory, 7 (3), 2001, pág.279-306.

Foot, P., "The Problem of Abortion and the Doctrine of the Double Effect", The Oxford Review, 5, 1967, pág.5-15.

Frederick, D., "Pro-tanto versus absolute rights", The Philosophical Forum, 2014, pág.375- 394.

Guastini, R., “Antinomias y lagunas”, Jurídica-Anuario, 1995, pág.437450.

Guastini, R., Distinguiendo, Barcelona, Gedisa, 1999.

Guastini, R., "Insiemi strutturati di norme. Contributi di Bobbio alla teoria dei sistemi normativi", Analisi e Diritto, 2004, 103-117.

Guastini, R., "Il diritto", en Pazé, V., (a cura di), L'opera di Norberto Bobbio. Itinerari di lettura, Milano, Franco Angeli, 2005. 
Mauricio Maldonado Muñoz

Guastini, R., Interpretare e argomentare, Milano, Giuffrè, 2011.

Guastini, R., La sintaxis del derecho, Madrid, Marcial Pons, 2016.

Hare, R.M., Moral Thinking. Its Levels, Method, and Point, Oxford, Clarendon Press, 1981.

Hart, H.L.A., Essays on Bentham. Studies in Jurisprudence and Political Theory, Oxford, Clarendon Press, 1982.

Hart, H.L.A., "Teoría de Kelsen sobre la unidad del derecho", Boletín Mexicano de Derecho Comparado, 21, 1974, pág.105-140.

Jori, M., Del diritto inesistente, Pisa, ETS, 2010.

Lariguet, G., "Dilemas morales y derecho. Una crítica a Martínez Zorrilla", Discusiones, 8, 2008, pág.55-105.

MacConnell, T., "Interpersonal moral conflicts", American Philosophical Quarterly, 25 (1), 1998, pág.25-35.

MacIntyre, A., "Moral Dilemmas", Philosophy and Phenomenological Research, 50, 1990, pág.367-382.

Maldonado Muñoz, M., "Conflictivismo y anti-conflictivismo en los derechos fundamentales”, Diritto \& Questioni pubbliche, 16 (2), 2016, pág.105-131.

Marmor, A., "On the Limits of Rights", Law and Philosophy, 16, 1997, pág.1-18.

Martínez Zorrilla, D., Conflictos constitucionales, ponderación e indeterminación normativa, Madrid, Marcial Pons, 2007.

Martínez Zorrilla, D., "Dilemas morales y derecho", Discusiones, 8, 2008, pág.17-54.

Martínez Zorrilla, D., "Respuestas a los participantes", Discusiones, 8, 2008, pág.135-172.

Martínez Zorrilla, D., "Conflictos normativos", en Fabra Zamora, J.L., Núñez Vaquero, A., Enciclopedia de Filosofia y Teoría del Derecho, Volumen 2, Ciudad de México, UNAM, 2015.

Mendonca, D., "Sobre el concepto de dilema moral", Discusiones, 8, 2008, pág.117-127.

Moreso, J.J., "Dilemas morales, derecho y la decisión de Sophie", Discusiones, 8, 2008, pág.7-16.

Moreso, J.J., "Conflictos entre principios constitucionales", en Carbonell, M., (ed.), Neoconstitucionalismo(s), Madrid, Trotta, 2009. 
Dilemas morales, conflictos entre derechos y conflictos...

Nash, J., "Non-cooperative games", Annals of Mathematics, 54 (2), 1951, pág.286-295.

Nussbaum, M., "Aeschylus and Practical Conflict", Ethics, 95 (2), 1985, pág.233-267.

Oberdiek, J., "Lost in Moral Space: on the infringing/violating distinction and its place in the theory of rights", Law and Philosophy, 23, 2004, pág.325-346;

Pino, G., "Conflictos entre derechos fundamentales. Una crítica a Luigi Ferrajoli”, Doxa, 32, 2009, pág.649-650.

Raz, J., "Personal Practical Conflicts", en Baumann, P., Betzler, M., (eds.), Practical Conflicts. New Philosophical Essays, Cambridge, Cambridge University Press, 2004,

pp. 172-196.

Rivera López, E., "Dilemas morales, discrecionalidad y azar", Discusiones, 8, 2008, pág.107- 116.

Richardson, H.S., "Specifying Norms as a Way to Resolve Concrete Ethical Problems", Philosophy \& Public Affairs, 19 (4), 1990, pág.279310.

Steiner, H., An essay on rights, Oxford, Blackwell, 1994.

Shafer-Landau, R., "Specifying Absolute Rights", Arizona Law Review, 37, 1995, pág.209- 225.

Sinnott-Armstrong, W., "Moral Dilemmas and Incomparability", American Philosophical Quarterly, 22 (4), 1985, pág.321-329.

Thomson, J.J., "Killing, Letting Die, and the Trolley Problem", The Monist, 59, 1976, pág.204-217.

Thomson, J.J., "Some Ruminations on Rights", Arizona Law Review, 19, 1977, pág.46-60.

von Wright, G.H., "Valor, norma y acción en mis escritos filosóficos.

Con un epílogo cartesiano", Doxa, Cuadernos de filosofia del derecho, 26, 2003, pág.37-38.

Waldron, J., "Rights in conflict", Ethics, 99 (3), 1989, pág.503-519.

Webber, G.C., The Negotiable Constitution: On the Limitation of Rights, Cambridge, Cambridge University Press, 2009.

Wellman, C.H., "On Conflicts Between Rights", Law and Philosophy, 14 (3-4), 1995, pág.271-295. 